\title{
Real-time monitoring of liver fibrosis through embedded sensors in a microphysiological system
}

\author{
Hafiz Muhammad Umer Faroogi ${ }^{1 \dagger}$, Bohye Kang ${ }^{1 \dagger}$, Muhammad Asad Ullah Khalid', \\ Abdul Rahim Chethikkattuveli Salih', Kinam Hyun', Sung Hyuk Park', Dongeun Huh² and Kyung Hyun Choi ${ }^{\text {** }}$
}

\begin{abstract}
Hepatic fibrosis is a foreshadowing of future adverse events like liver cirrhosis, liver failure, and cancer. Hepatic stellate cell activation is the main event of liver fibrosis, which results in excessive extracellular matrix deposition and hepatic parenchyma's disintegration. Several biochemical and molecular assays have been introduced for in vitro study of the hepatic fibrosis progression. However, they do not forecast real-time events happening to the in vitro models. Transepithelial electrical resistance (TEER) is used in cell culture science to measure cell monolayer barrier integrity. Herein, we explored TEER measurement's utility for monitoring fibrosis development in a dynamic cell culture microphysiological system. Immortal HepG2 cells and fibroblasts were co-cultured, and transforming growth factor $\beta 1$ (TGF$\beta 1$ ) was used as a fibrosis stimulus to create a liver fibrosis-on-chip model. A glass chip-based embedded TEER and reactive oxygen species (ROS) sensors were employed to gauge the effect of TGF- $\beta 1$ within the microphysiological system, which promotes a positive feedback response in fibrosis development. Furthermore, albumin, Urea, CYP450 measurements, and immunofluorescent microscopy were performed to correlate the following data with embedded sensors responses. We found that chip embedded electrochemical sensors could be used as a potential substitute for conventional end-point assays for studying fibrosis in microphysiological systems.
\end{abstract}

Keywords: Liver fibrosis-on-chip, TEER sensor, ROS sensor, Embedded sensors, TGF- $\beta 1$

\section{Introduction}

Hepatic tissue's regenerative capacity safeguards the liver from acute injury even when a significant part of the liver is damaged or excised [1]. Liver is capable of restoring its histology and physiology during the process of regeneration. However, chronic liver abnormalities result in impaired regenerative capacity, which results in a robust inflammatory response, accelerated apoptosis, necrosis, and eventually scar tissue formation (wound healing process). The wound healing process is instrumental in acute

\footnotetext{
*Correspondence: amm@jejunu.ac.kr

${ }^{\dagger}$ Hafiz Muhammad Umer Farooqi and Bohye Kang contributed equally to this manuscript

${ }^{1}$ Department of Mechatronics Engineering, Jeju National University,

Jeju-si, Republic of Korea

Full list of author information is available at the end of the article
}

liver injuries; however, in the case of chronic liver pathologies, scar tissue disintegrates the liver parenchyma, interrupt blood flow, and eventually results in disruption of cohesive cell-cell tight junction proteins (TJPs) [2, 3]. The scar tissue is mainly composed of the extracellular matrix (ECM) proteins collagens, proteoglycans, and glycoproteins, especially cross-linked collagen type I and type III [1]. Its abnormal aggregation is called liver fibrosis. Hypoxic injury or oxidative stress and necroinflammation are considered allied mediators of hepatic stellate cell (HSC) activation, the primary liver fibrosis mediator. Other factors that trigger HSC activation include reactive oxygen species (ROS), lipopolysaccharide, paracrine cytokine stimulation, apoptotic bodies, and resident Kupffer cells [4]. The advanced form of liver fibrosis is referred to as cirrhosis. Fibrotic liver and cirrhosis are the 
main risk factors for liver cancer and have become a significant concern worldwide [5]. Cellular oxidative stress (OS) is a state in which cell antioxidant and pro-oxidant redox balance permute in favor of pro-oxidant condition, which leads to considerable cell damage. Increased production of reactive nitrogen species or ROS or decreased antioxidant levels are the leading causes of OS. ROS perform several vital roles in physiological conditions such as host defense against microbes, cell signaling pathways, and cell cycle regulation [6]. ROS are extremely unstable and consist of hydrogen peroxide $\left(\mathrm{H}_{2} \mathrm{O}_{2}\right)$, superoxide anions $\left(\mathrm{O}_{2}{ }^{-}\right)$, and hydroxyl radicals (HO.) [7]. However, $\mathrm{O}_{2}{ }^{-}$is extremely unstable; hence, superoxide dismutase (antioxidant enzyme) promptly converts it into $\mathrm{H}_{2} \mathrm{O}_{2}$. Which is relatively stable, long-lived, and lacks ionic charge, making it freely diffusible and catastrophic to intracellular macromolecules, including cell-cell tight junction proteins. An increased ROS level in the endoplasmic reticulum, especially $\mathrm{H}_{2} \mathrm{O}_{2}$, results from excessive utilization of reduced glutathione ends up in increased oxidized misfolded proteins and release of calcium from ER [8]. It eventually results in oxidative stress in mitochondria, ultimately leading to apoptosis and cellular injury. Unfortunately, no effective anti-fibrosis treatment is available, and current therapies for curing liver fibrosis and cirrhosis are primarily limited to alleviating chronic stresses. The lack of robust and repeatable in vitro models for liver fibrosis is one of the primary obstacles in discovering efficient treatments [9].

In recent years, organ-on-chip (OOC) technology based on microfluidics emerged as a potential replacement for animal modeling. In this technology, microfluidic chips provide an in-vivo microenvironment and nurture biological tissue with physiological shear stress. Hence, these are becoming a popular choice for disease modeling, reverse engineering of human organs, and pharmaceutical testing. OOC is also termed as microphysiological systems (MPS) [10]. To date, several liveron-chip (LOC) models have been introduced for studying hepatic anomalies $[11,12]$ and compound toxicity $[13$, 14]. Lee et al. developed a liver fibrosis-on-a-chip model to investigate the impact of gelatin bioinks through cell printing technology. They used pre-activated HSC; however, liver fibrosis development was not examined in realtime [15]. Jang et al. identified liver fibrosis biomarkers based on the activation of stellate cells and liver function enzymes using a liver-chip [14]. Huang et al. proposed an immunosensor for screening liver fibrosis markers on a chip, but it has not been tested in microfluidics with hepatic cells [16]. Zhou et al. studied paracrine cell signaling within liver-on-a-chip and targeted liver fibrotic biomarker TGF- $\beta 1$ [17].
Trans-epithelial electrical resistance (TEER) and electrical cell-substrate impedance sensing (ECIS) are the unique approaches to evaluate real-time impedance measurement of biological tissues [18]. TEER estimation is a quick and non-invasive method to measure in vitro cells' differentiation and the epithelial monolayer integrity [19]. It was previously employed in OOC to assess the cell monolayer barrier integrity, cell viability, cell-cell tight junction formation, and drug toxicity response [13, 20, 21]. However, TEER impedance spectroscopy has not been used to monitor liver fibrosis development in a microfluidic system. Commercial TEER and ECIS modules such as Millicell ERS, EVOM2, REAL-TIME Roche xCELLigence Analysis (RTCA), and AutoLab potentiostat are mostly used in the reported literature [20-27]. The micro-size of microphysiological organ chips makes it harder to incorporate the impedance measuring electrodes into the microfluidic systems; however, previously, electrodes have been incorporated into microfluidic chips made of polydimethylsiloxane (PDMS) [21]. We explored this opportunity and used a validated embedded indium tin oxide (ITO) based transparent TEER sensor for studying liver fibrosis.

Fluorescent microscopy and chemiluminescence assays are a popular choice among researchers for ROS measurement [28-30]. However, a few efforts have been made for the electrochemical detection of ROS in microfluidic systems. Ko et al. employed bimetallic nanoparticles to continuously detect hydrogen peroxide in microfluidic devices for up to $100 \mathrm{~min}$ [31]. Jin et al. modified a microfluidic chip by integrating a flexible electrochemical sensor for monitoring vascular transduction and evaluated the effect of $\mathrm{H}_{2} \mathrm{O}_{2}$ on vascular mechanotransduction [32]. End-point assays are typical for the evaluation of LOC models, but biologicals processes occur in real-time. Hence, end-point assessment cannot picture the actual biological events happening in a MPS [33]. In this study, considering ECM, TJPs, and ROS's role, a liver fibrosis-on-chip model was modeled to check the feasibility of integrated TEER and newly developed ROS sensors for monitoring fibrosis development. TEER sensor was printed on-chip using chemical vapor deposition (CVD) technique, which has been previously described [34]. While the ROS sensor pattern used a solution-based inkjet printing technique on the glass chip to detect $\mathrm{H}_{2} \mathrm{O}_{2}$. The effect of different ECM on the attachment of liver and fibroblasts cells to the microfluidic glass chip was also evaluated. The sensor data revealed that the chip embedded TEER sensor and ROS sensor could monitor liver fibrosis development. We further performed biomarker assays to correlate the integrated sensor data. The results were compared, and it can be conferred that 
TEER and ROS sensors can serve as a substitute for conventional end-point assays.

\section{Experimental}

\subsection{Microfluidic chip fabrication}

The microfluidic chip was constructed with the two top and bottom glass chips (soda-lime glass, $56 \mathrm{~mm}$ long, $41 \mathrm{~mm}$ wide, and $1.1 \mathrm{~mm}$ thick) (Fig. 1b). A multi-head $3 \mathrm{D}$ printer was used to print the microfluidic channel on the top glass with PDMS (Sylgard 184, Dow Corning, USA). The glass chips were degassed thoroughly before loading into the printer stage, the fabrication height and width of the channels were set to be $300 \mu \mathrm{m}$ and $800 \mu \mathrm{m}$, respectively. A customized magnetic chip holder was used to assemble the top and bottom glasses of the microfluidic chip. Additionally, the silicon gaskets were placed in the magnetic chip holder to avoid leakage.

\subsection{Cell seeding and liver fibrosis on microfluidic chip}

A human-derived immortal HepG2 hepatoma cell line (Korea Cell Line Bank, South Korea) and human foreskin fibroblasts cell line Hs68 (Korea Cell Line Bank,
South Korea) were utilized to create a co-culture model of hepatocytes and fibroblast. Both cell lines were grown in Roswell Park Memorial Institute (RPMI) 1640 cell culture media (cat\# 11875093, ThermoFisher, USA) supplemented with $10 \%$ fetal bovine serum (FBS) (cat\# 16000044, ThermoFisher, USA) and $1 \% \mathrm{v} / \mathrm{v}$ penicillin/ streptomycin $(\mathrm{P} / \mathrm{S})$ antibiotic solution for cell culture (cat\# 15070063, ThermoFisher, USA). The HepG2 cells and Hs68 cells were kept in a humidified incubator (with $5 \% \mathrm{CO}_{2}$ at $37{ }^{\circ} \mathrm{C}$ ). All glass chips were sterilized with $90 \%$ isopropyl alcohol and UV irradiated for $1 \mathrm{~h}$ in a biosafety cabinet before use. A magnetic ECM \& cell seeding kit was used to apply the ECM and seeding cells on microfluidic glass chips' cell culture area. ECM solutions of collagen, poly-L-lysine, and fibronectin were used before cell seeding for cell attachment to the microfluidic chip surface. The cells were expanded and passaged thrice before seeding on the microfluidic chip at the physiological ratio of 1:8. Cells were allowed to attach the microfluidic chip for $4 \mathrm{~h}$ in a standard cell culture incubator at $37{ }^{\circ} \mathrm{C}$ with $5 \% \mathrm{CO}_{2}$. After that, the glass chip top and bottom parts were assembled in a magnetic chip holder.

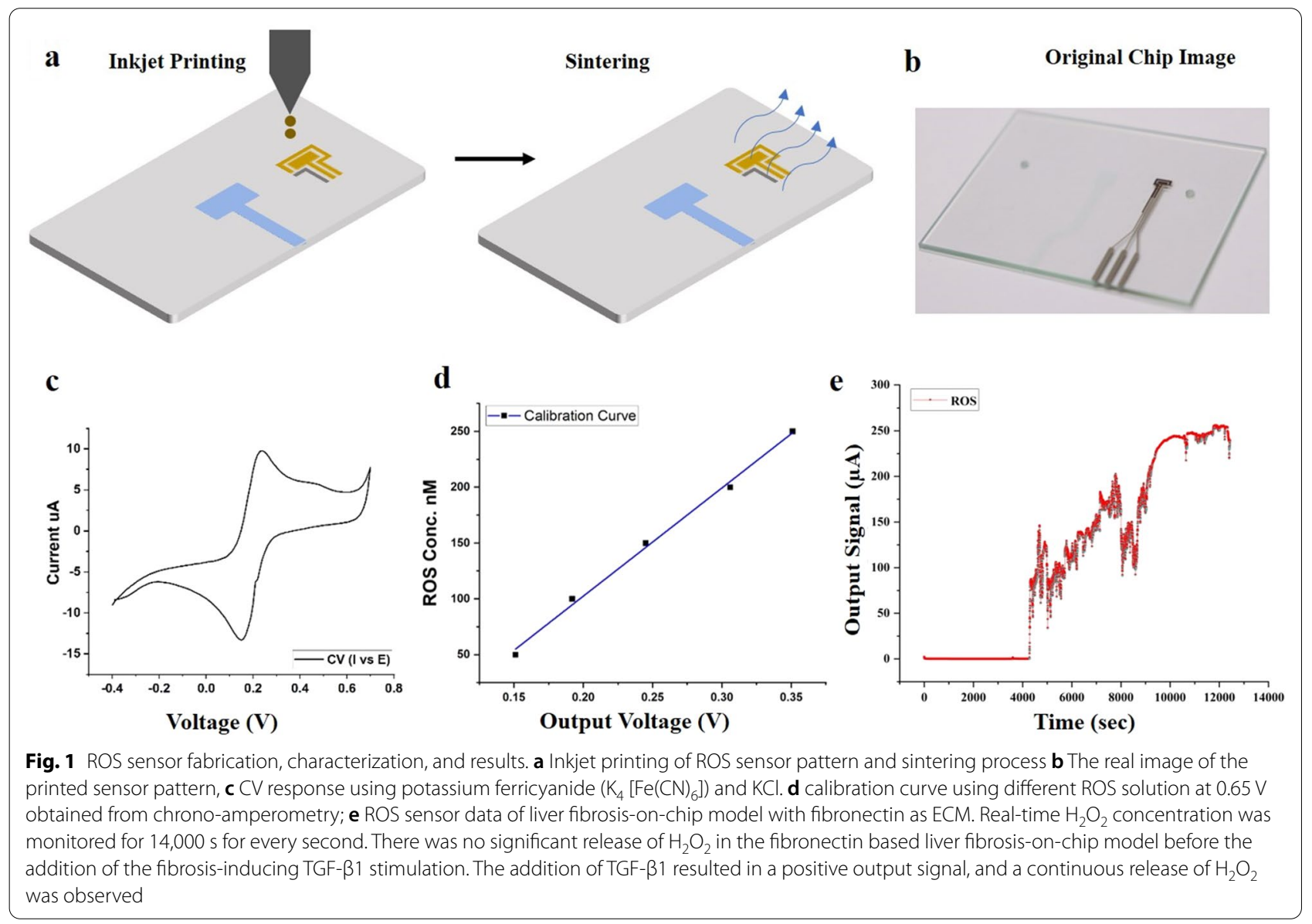




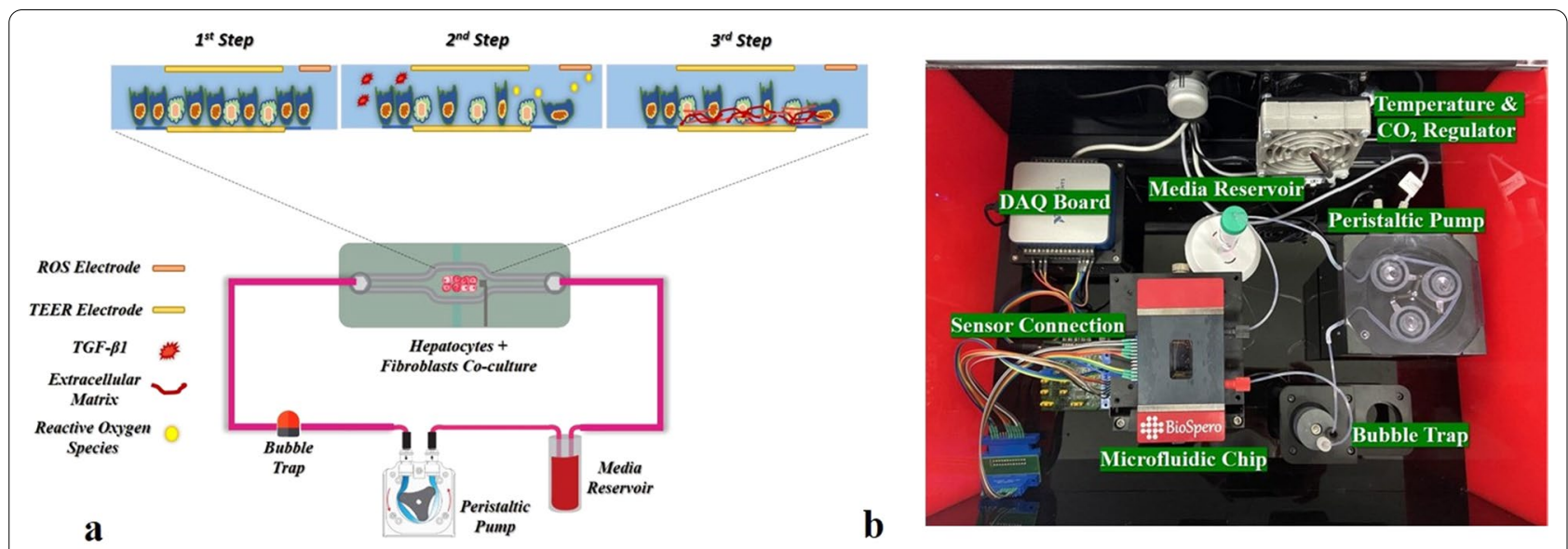

Fig. 2 a The liver fibrosis-on-chip schematic; $\mathbf{b}$ The actual image of the liver fibrosis-on-chip device and associated components

The microfluidic chip was placed in the custom-built microfluidic platform to form a monolayer in a dynamic cell culture environment, as shown in Fig. 2b. A cell culture media reservoir of $5 \mathrm{~mL}$ capacity was placed and connected with the microfluidic tubing Fig. 2b. The peristaltic pump's speed was fixed at $60 \mu \mathrm{L} / \mathrm{min}$ to induce the shear stress of $0.5 \mathrm{dyn} / \mathrm{cm}^{2}$. Recombinant human TGF- $\beta 1$ protein (cat\# ab50036 abcam, USA) at the concentration of $5 \mathrm{ng} / \mathrm{mL}$ was used to induce in vitro fibrosis. The shear stress calculation formula is given below as Eq. 1. [35]

$$
\tau=\frac{6 \mu Q}{w h^{2}},
$$

whereas here, " $\mu$ " signifies viscosity of the cell culture medium, " $Q$ " exhibits the flow rate of the media, " $w$ " represents the width and height of the channel are characterized by " $h$."

\subsection{Sensor fabrication and characterization}

TEER sensor was fabricated on both glass chips by printing a $500 \mathrm{~nm}$ ITO pattern using the CVD technique. The sensor was characterized as described previously [34]. Whereas the ROS sensor pattern was printed on the top glass chip downstream using an in-house multi-head 3D printer. A schematic of the process has been shown in Fig. 1a. The fabrication process involved first cleaning the substrate using ethanol, acetone, and DI water. After drying the chip surface, oxygen plasma was treated for $20 \mathrm{~s}$ to clean the substrate. The print speed was set at $1 \mathrm{~ms}^{-1}$ to fabricate gold and silver electrodes. Gold ( $\mathrm{Au}$ ) ink [cat\# Au-LT-20 (20 wt\%) Fraunhofer, Germany] was printed first dried at $40{ }^{\circ} \mathrm{C}$ for $10 \mathrm{~min}$ and sintered at $190{ }^{\circ} \mathrm{C}$ for $12 \mathrm{~h}$, followed by printing the silver (Ag) ink [cat\# sliver (TEC-PA-060) Solvent (DA-030) INKtec, Republic of KOREA] and sintering at $130{ }^{\circ} \mathrm{C}$ for $20 \mathrm{~min}$. The sensors were characterized using a commercial PalmSens4 portable system (PalmSens, Netherlands) for cyclic voltammetry $(\mathrm{CV})$ with standard solutions of $10 \mathrm{mM}$ potassium ferricyanide $\left(\mathrm{K}_{4}\left[\mathrm{Fe}(\mathrm{CN})_{6}\right]\right)$ and $0.1 \mathrm{M} \mathrm{KCl}$, as shown in Fig. 1c, d. However, a custom-developed system was used for the sensor's chronoamperometric response to plot the sensor's calibration curve, which has been shown in Fig. 2b. The sensor was then washed with Phosphate buffered saline (PBS) and double distilled water for further use in the experiments.

\subsection{ECM evaluation in the liver-on-chip device}

Three different ECM have been used for studying the effect of ECM on the cell attachment to the microfluidic glass chip surface. Rat Tail Collagen (type I) (cat\#C3867-1 VL, Sigma-Aldrich, South Korea) was used at concentrations of $200 \mu \mathrm{g} / \mathrm{mL}$ in PBS (cat\# 10010023, ThermoFisher Scientific, USA). Poly-L-lysine $1 \mathrm{mg} / \mathrm{mL}$ (cat\# 0403, ScienCell, USA) was diluted in sterile double distilled water to get $5 \mu \mathrm{g} / \mathrm{mL}$ concentrations. According to the manufacturer's instruction, fibronectin $1 \mathrm{mg} / \mathrm{mL}$ (cat\# 33010018, ThermoFisher, USA) was resuspended in $1 \mathrm{~mL}$ of sterile double distilled water. Fibronectin was further mixed with the PBS to get the concentrations of $25 \mu \mathrm{g} /$ $\mathrm{mL}$. The $400 \mu \mathrm{L}$ of each ECM solution was applied to the microfluidic chips' cell culture area using the ECM \& cell seeding kit. The chips were then incubated overnight at $4{ }^{\circ} \mathrm{C}$ in a sterile environment.

\subsection{Albumin, urea, CYP450 enzyme measurements}

Albumin, urea, and CYP450 enzyme assays were performed as functional biomarkers of the hepatocytes. Human Albumin ELISA Kit (cat\# ab108787, Abcam, USA), Urea Assay Kit (cat\# KA1652, Abnova, USA), and P450-Glo CYP3A4 Assay Kit (cat\# V9001, Promega, 
USA) were used for albumin, urea, and CYP3A4 quantification, respectively. In brief, cell culture media samples were collected at specified time points and stored at $-80{ }^{\circ} \mathrm{C}$. While CYP3A4 assay was performed by following the manufacturer's instructions with slight modifications. Media samples were thawed at $37{ }^{\circ} \mathrm{C}$ in a water bath before experiments. A microplate reader (SpectraMax i3 Multimode Microplate Reader, Molecular Devices, USA) was used for taking readings by following the manufacturer's instructions.

\subsection{Live/dead assay}

The assay was performed according to the manufacturer's manual (LIVE/DEAD Viability/Cytotoxicity Kit, for mammalian cells, cat\# L3224, ThermoFisher, USA). Briefly, the microfluidic chip's cell culture area was washed three times with Dulbecco's phosphate buffered saline (DPBS) and covered with a $300 \mu \mathrm{L}$ solution of live/dead assay reagents. The chip was incubated in a humidified cell culture incubator $\left(5 \% \mathrm{CO}_{2}\right.$ at $\left.37{ }^{\circ} \mathrm{C}\right)$ for $30 \mathrm{~min}$. Then, the cell surface was cleaned with DPBS and mounted with a coverslip. After that confocal laser scanning microscope (CLSM) (Olympus, model \# FV122, Olympus, Japan) was used at the excitation of 530$560 \mathrm{~nm}$ and emission of 530-645 $\mathrm{nm}$ for taking images. The confocal images were processed for live and dead cell count by using ImageJ software (Version 1.52p, NIH, USA).

\subsection{ZO-1, a-SMA, and collagen immunofluorescence microscopy}

The chip's cell culture area was rinsed thrice with prewarmed 1× DPBS (cat\# 14190144, ThermoFisher, US) solution and fixed in 4\% paraformaldehyde. After that, a blocking solution (5\% BSA/PBS) was used, and chips were incubated with primary antibodies against ZO-1 (cat\# 33-9100, ThermoFisher, USA), alpha-smooth muscle actin ( $\alpha$-SMA) (cat\# 14-9760-82, ThermoFisher, USA) and collagen type I (cat\# PA1-26204, ThermoFisher, USA). The secondary antibodies used were $F\left(a^{\prime}\right) 2$-goat anti-rabbit $\operatorname{IgG}(\mathrm{H}+\mathrm{L})$ (cat\# A-21430), superclonoal ${ }^{\mathrm{TM}}$ recombinant secondary antibody (cat\# A28175, ThermoFisher, USA) and goat anti-mouse $(\mathrm{H}+\mathrm{L})$, super clonal recombinant secondary antibody, Alexa flour 488 (cat\# A28175, ThermoFisher, USA). While 4',6-diamidino-2-phenylindole (DAPI) (cat\# 127M4055V, SigmaAldrich, USA) was used for cell nucleus staining. A CLSM (Olympus, model \# FV122, Olympus, Japan) was used for cell visualization and capturing the images.

\section{Results and discussion}

\subsection{Real-time monitoring of liver fibrosis-on-chip with integrated sensors}

The microfluidic chips and platform were set up, as mentioned in Fig. 2, and the real-time monitoring of the liver MPS was carried out for $144 \mathrm{~h}$ for collecting control data. Static cell culture systems are facile, yet they lack mechanical stimulation such as shear stress. Physiological shear stress induces better monolayer formation and
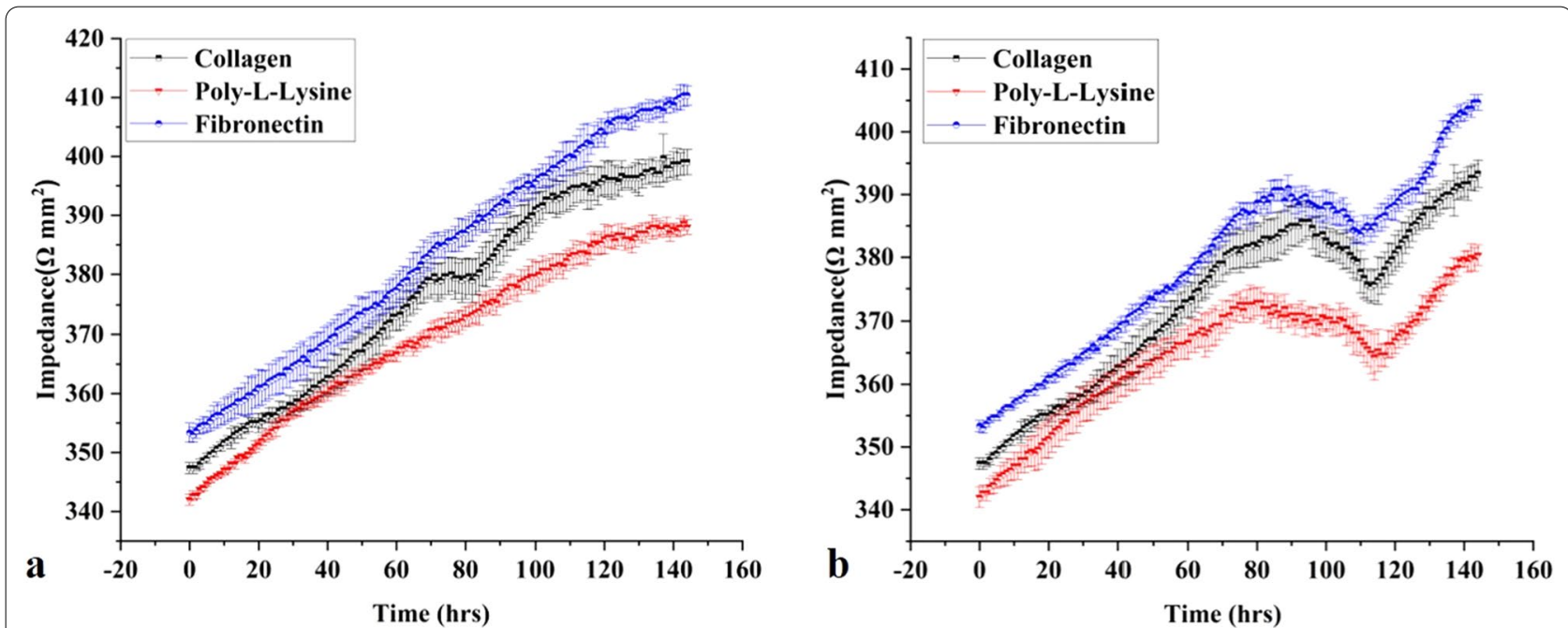

Fig. 3 a Real-time TEER data graph presents the comparative impedance to different ECM time graphs in the liver MPS (data presented as mean \pm SD). $\mathbf{b}$ Real-time TEER data graph illustrates the comparative impedance to the time graph of different ECM and TGF- $\beta 1$ responses in the liver fibrosis-on-chip model. The TEER values increased till the formation of a monolayer at $72 \mathrm{~h}$. TGF- $\beta 1$ was introduced in the MPS at $72 \mathrm{~h}$, which results in the drop of TEER values due to cell-cell tight junction disruption and activation of fibroblasts. Activated fibroblasts produced ECM, which eventually increased the TEER values (data presented as mean \pm SD) 
CYP450 enzyme activity [36]. Hence, the shear stress of $0.5 \mathrm{dyn} / \mathrm{cm}^{2}$ was applied to achieve better monolayer formation than static cell culture [13, 36, 37]. The TEER values of liver MPS were taken at every 1-h interval for $144 \mathrm{~h}$, as shown in Fig. 3a. The TEER increase concerning the time indicated resultant co-cultured cell monolayer formation of the microphysiological environment due to the cell growth, division, and cell-cell tight junction formation. The monolayer formed on the 3rd day or $72 \mathrm{~h}$. In the current study, the TEER value $370-390 \Omega / \mathrm{mm}^{2}$ represents a monolayer formation. However, in previous research, the TEER range of $345-395 \Omega / \mathrm{mm}^{2}$ indicates a compact HepG2 monolayer formation [13]. The difference from the previously reported TEER range could be due to the co-culture of HepG2 cells with fibroblasts in the present work. However, the TEER values were kept increasing throughout the experiment (Fig. 3a). It was due to the ample supply of FBS within the microphysiological system by cell culture media. 10\% FBS in cell culture media results in continuously increasing TEER values and tighter cell-cell tight junction formation compared to serum-free or serum reduced cell culture media [38]. TGF- $\beta 1$ in the concentration of $5 \mathrm{ng} / \mathrm{mL}$ was used as a stimulant to induce fibrosis in the liver fibrosis-onchip model [39]. The stimulus was introduced in the chip at $72 \mathrm{~h}$ of the cell culture. In the liver fibrosis-onchip model, after the addition of stimulants in the MPS, the TEER values started decreasing within $24 \mathrm{~h}$ (Fig. 3b). They kept dropping for $48 \mathrm{~h}$ due to the disruption of cellcell TJPs. The TEER value decreased till the 105 th $\pm 10 \mathrm{~h}$, as shown in Fig. 3b. TGF- $\beta 1$ is known to disrupt cell-cell TJPs in epithelial tissues $[40,41]$. After that, an increase was observed in the TEER values due to the release and deposition of ECM proteins by the activated fibroblasts in the liver fibrosis-on-chip model. According to published literature, an increase in ECM deposition results in higher TEER values [42-45]. The embedded ROS sensor depicted the freedom of release of $\mathrm{H}_{2} \mathrm{O}_{2}$ in fibronectin based liver fibrosis-on-chip model in response to the stimulant Fig. 1e. TGF- $\beta 1$ is known to induce redox imbalance in hepatocytes and produce ROS significantly, further generating a positive feedback system for activating adjacent fibroblasts [46, 47]. ROS sensor response was recorded $1 \mathrm{~h}$ before introducing the fibrosis-inducing stimulus (TGF- $\beta 1$ ). There was no significant $\mathrm{H}_{2} \mathrm{O}_{2}$ release observed during that time. However, TGF- $\beta 1$ stimulation gave rise to the production of $\mathrm{H}_{2} \mathrm{O}_{2}$, and the ROS production started increasing. It is due to the negative impact of the TGF- $\beta 1$ on the hepatocytes. The decrease in ROS release at the 2nd hour could be due to the reduction of cell viability [48]. Dynamic cell culture microenvironment of liver fibrosis-on-chip model results in repeated TGF- $\beta 1$ exposure to resident cells. This induces more
ROS production and $\mathrm{H}_{2} \mathrm{O}_{2}$ release with the passage of time. Overall, the ROS concentration was kept growing within the liver fibrosis-on-chip model, which can be the reason of HepG2 cell stress and fibroblasts activation and resultant ECM production.

\subsection{Albumin, urea, and CYP450 measurements}

Albumin and urea are the functional biomarkers and reflect the pathophysiological state of hepatocytes [49]. Albumin and urea concentrations of the control MPS were measured after every $12 \mathrm{~h}$ until the experiment's termination on the 6th day. There was a consistent increase in the hepatocytes' albumin release, representing the MPS' overall health condition, as shown in Fig. 4a. The cell viability (live/dead assay) data further confirms the claim (Fig. 5a, b). Similarly, urea release was also consistent and physiological throughout the experiment, which depicts the MPS's physiological, metabolic condition, as shown in Fig. 1b. Cytochrome P450 (CYP450) is a group of heme oxygenase enzymes and plays a pivotal role in the metabolism of drugs and biotransformation of several biological molecules. CYP3A4 is a subgroup of the CYP450 family, responsible for $50 \%$ commercially available drugs and known to generate a significant amount of ROS during drug metabolism [50]. In liver MPS CYP3A4 activity was one fold more than static cell culture systems, which can be attributed to the shear stress and superior in vitro microenvironment compared to the conventional cell culture system (Fig. 5c) [51].

In the liver fibrosis-on-chip model, albumin and urea release compromised significantly after treatment with TGF- $\beta 1$ for modeling fibrosis. TGF- $\beta 1$ suppresses the activity of CYP3A4 activity and results in a lack of drug response for anti-fibrosis therapy [52]. ROS are also an essential player in reducing the efficiency of CYP3A4 by altering the protein secretion involved in autocrine and paracrine signaling [53]. ROS is often a common target of various anti-fibrosis drugs to refrain it in liver cirrhosis progression $[54,55]$. During liver fibrosis-on-chip model experiments, there was a twofold decrease in the amount of CYP3A4 after TGF- $\beta 1$ stimulation, as shown in Fig. $5 c$. TGF- $\beta 1$ is known to decrease the CYP3A4 activity by several pathways, such as the hPXR pathway [52]. The addition of fibrosis-inducing stimulus also downregulated the albumin release by four-folds, as shown in Fig. 4a. In static cell culture conditions, TGF- $\beta 1$ can reduce the albumin synthesis up to five folds [56]. Similarly, the urea production was also reduced in response to the stimulus Fig. 4b. It is evident from other OOC studies that stress stimuli harm hepatocyte metabolism and results in less urea formation [57-59]. 

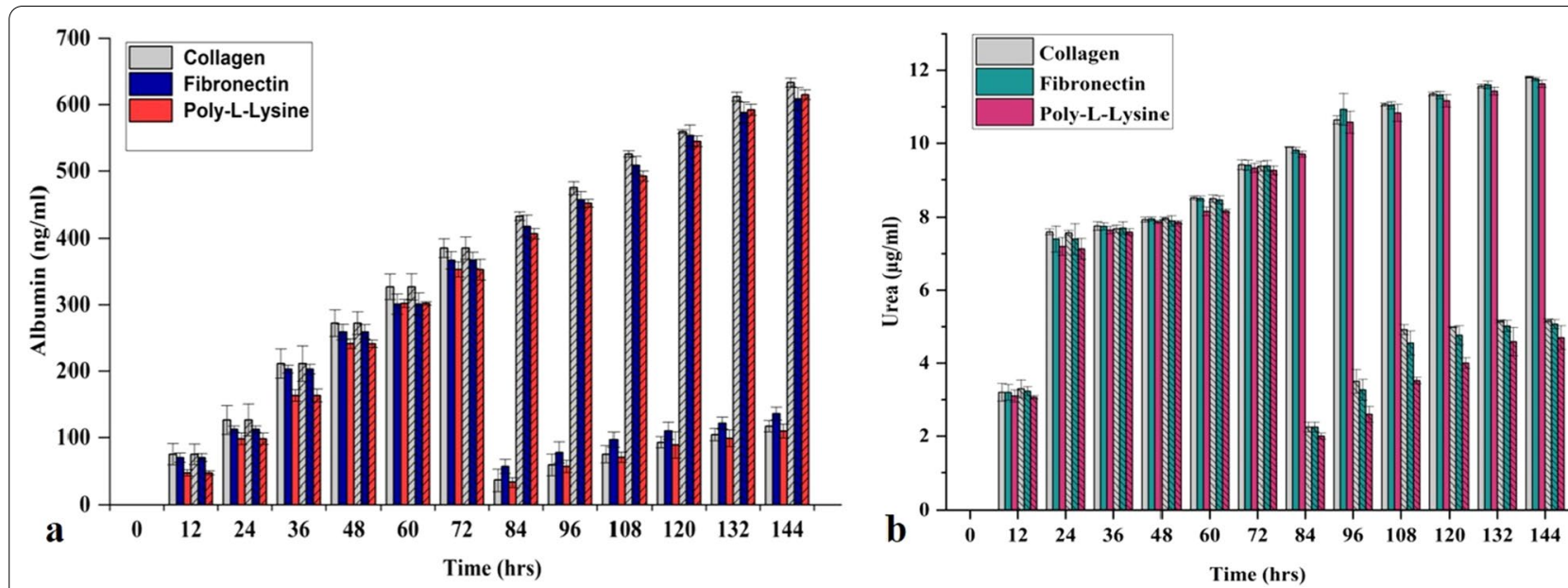

Fig. 4 a Albumin release by liver MPS in control and fibrotic condition for $144 \mathrm{~h}$. A sudden decrease in albumin concentration was noted after applying a fibrosis stimulus (TGF- $\beta 1$ ) at $72 \mathrm{~h}$ (data presented as mean \pm SD, bar column with cross lines representing the control values). b Urea production by liver MPS in control and fibrotic condition for $144 \mathrm{~h}$. TGF- $\beta 1$ stimulation for fibrosis induction at $72 \mathrm{~h}$ reduced the urea release by the hepatocytes [data presented as mean \pm standard deviation (SD) bar column without cross lines representing the control values]

\subsection{ZO-1, a-SMA, and collagen immunofluorescence microscopy and live/dead assay}

TJPs maintain a delicate balance to ensure a dynamic microenvironment of hepatic parenchyma and mesenchymal tissues. Pathophysiological stresses trigger the change and variation in liver TJPs. Liver TJPs are meant to change their expression in response to drugs, infections, and biological molecules. TJP-1 or zonula occludens-1 (ZO-1) protein expression was studied with the help of immunofluorescent microscopy. In control liver MPS experiments, the ZO-1 proteins were found intact around the hepatocytes. They showed tight junction formation, as shown in Fig. 6. That was the reason for the progressive increase in TEER values. $\alpha$-SMA is the characteristic marker of fibroblasts activation in response to various cytokines and inflammatory mediators. Hence, fibroblasts were examined without the activation by the fibrosis-inducing factor TGF- $\beta 1$. There was a negative $\alpha$-SMA expression in fibroblasts (Fig. 7). TGF$\beta 1$ is known for the dissolution of TJPs through RhoA/ ROCK signaling pathway in epithelial cells [60]. In the present study, the disruption of $\mathrm{ZO}-1$ protein was confirmed in response to TGF- $\beta 1$ stimulation, as shown in Fig. 6, which was why TEER values drop after treatment with fibrosis-inducing stimulus. In fibroblasts, treatment with TGF- $\beta 1$ resulted in their activation and subsequent $\alpha$-SMA expression, as shown in Fig. 7. Collagen is one of the primary components of liver ECM, and it can increase up to 10-folds during liver fibrosis [61]. Collagen immunofluorescent staining showed a significant amount of collagen deposition in the liver fibrosis-on-chip model in response to TGF- $\beta 1$ stimulation compared to liver
MPS, shown in Fig. 8. Liver fibrosis significantly compromises the activity and survival of hepatocytes. The deposition of increased ECM in the para and intracellular spaces disrupts the blood access to the hepatocyte and leads to cell starvation $[1,2]$. The accumulation of metabolites and oxidative stress further worse the fibrotic tissue [3]. In Liver MPS experiments, the cell viability was satisfactory, as shown in the figure. While in liver fibrosis-onchip, the cell viability decreased to $77 \%$ for fibronectin, $76 \%$ for collagen, and $73 \%$ for poly-1-lysine, as shown in Fig. $5 \mathrm{a}, \mathrm{b}$. TGF- $\beta 1$ exposure resulted in compromised cellular growth and survival.

\subsection{Impact of different ECM on liver fibrosis-on-chip model} ECM is a vital component of a cell culture system and provides a niche for cell differentiation and cell division. In organ-on-chip, several ECM components such as collagen, fibronectin, fibrinogen, laminin have been used to attach the cells to a surface or a porous membrane. ECM composition and constituents vary from organ to organ [62]. However, there is no standardization or consensus among the organ-on-chip researchers about ECM's choice for modeling MPSs. Collagen is the most commonly used ECM in OOC studies. Yet, the use of polyL-lysine in organ-on-chip technology for cell attachment is still not studied. In liver-on-chip studies, collagen and fibronectin are the most commonly used ECM [13, 59, $63,64]$. Here, we explored the choice of the most vibrant ECM for liver fibrosis-on-chip development and its effect on the TEER and ROS sensor response and biomarker yield. In control liver MPS experiments, all the ECM (collagen, fibronectin, and poly-L-lysine) provided good 


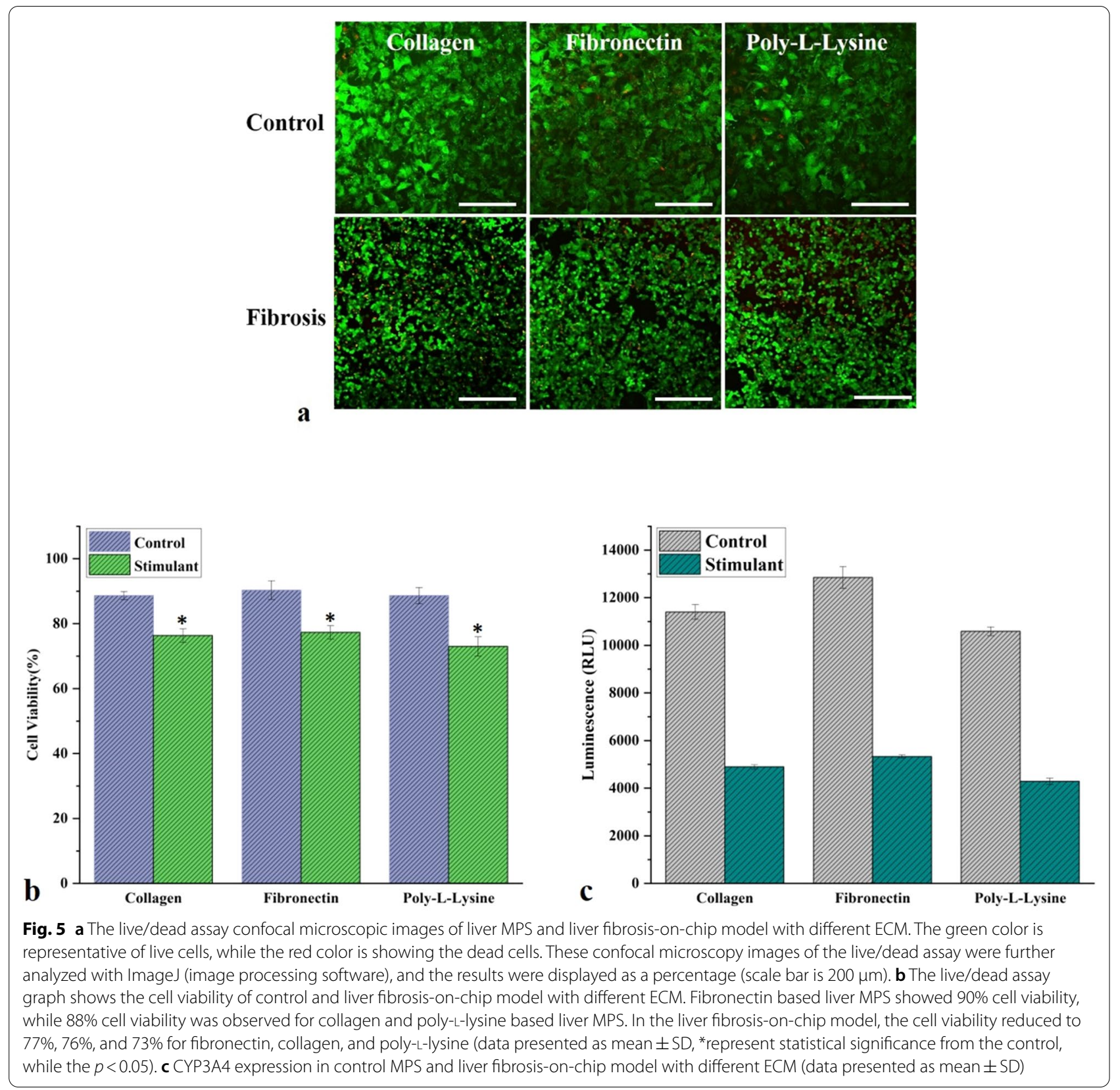

biomarker production and cell viability. Collagen and fibronectin were superior compared to the poly-L-lysine in terms of biomarker production and better cell viability. While fibronectin was found the most suitable ECM to model liver fibrosis-on-chip study using embedded electrochemical sensors. It has been found that all three ECM can be used for cell attachment to a glass based MPS surface. Even so, TEER values showed a variation among the use of different ECM. Poly-L-lysine based MPS showed the minimum TEER values and compared to the fibronectin and collagen-based MPS. Furthermore, ZO-1 confocal images showed lower expression of ZO-1 of poly-L-lysine based MPS. Contrary to that, fibronectin based MPS presented the highest TEER values and more ZO-1 expression than poly-L-lysine and collagen-based MPS.

There was significant variation in TEER sensor response with different ECM in the liver fibrosis-onchip case. Fibronectin based liver fibrosis-on-chip model showed the highest TEER values compared to the collagen and poly-L-lysine coated liver fibrosis-on-chip models. It can be attributed to the fibronectin's higher molecular weight and better cell attachment of the hepatocytes and fibroblasts as compared to other ECM based 


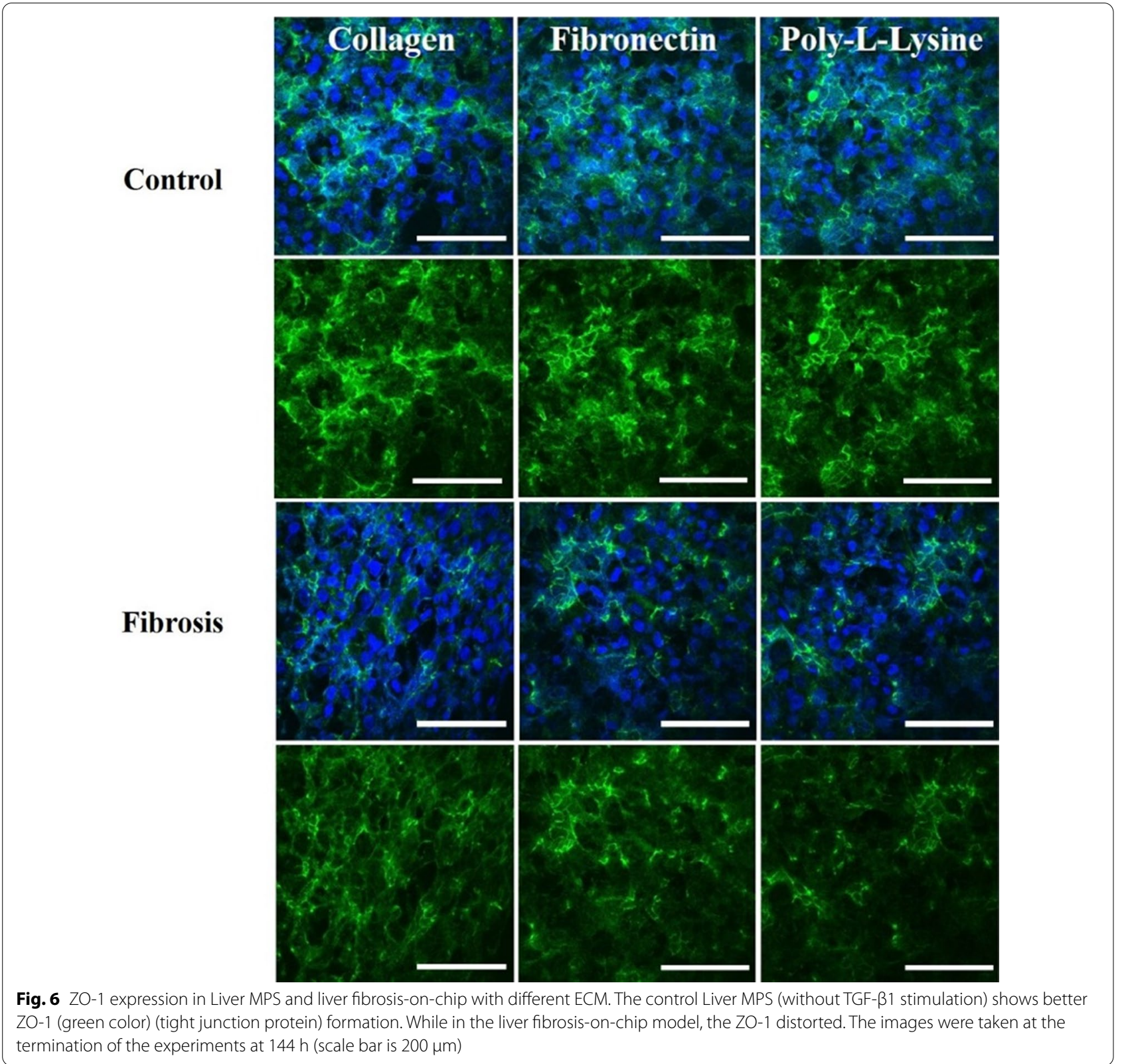

liver fibrosis-on-chip models. A chip embedded ROS sensor was applied, considering the importance of the fibronectin-based liver fibrosis-on-chip model, and the $\mathrm{H}_{2} \mathrm{O}_{2}$ concentration was monitored in real-time.

\section{Conclusion}

In this work, a liver microphysiological system was developed for the real-time monitoring of fibrosis development using embedded electrochemical sensors. A microfluidic glass chip was constructed, and an elastomeric microfluidic channel was fabricated onto an ITO surface using a $3 \mathrm{D}$ printer. CVD and $3 \mathrm{D}$ printing techniques were employed to print TEER and ROS sensor patterns on the microfluidic chip, respectively. A magnetic chip holder was utilized to hold together the chip components. During control experiments, sensor and biochemical assay data were collected. In the next step, fibrosis was induced in the liver MPS through a stimulus (TGF- $\beta 1$ ), and a liver fibrosis-on-chip model was constructed. After introducing the fibrosis-inducing stimulus, the TEER values started declining, and a positive ROS response was recorded. After $24 \mathrm{~h}$ of stimulus activity, the TEER values began increasing due to the activation of fibroblasts and ECM deposition within 

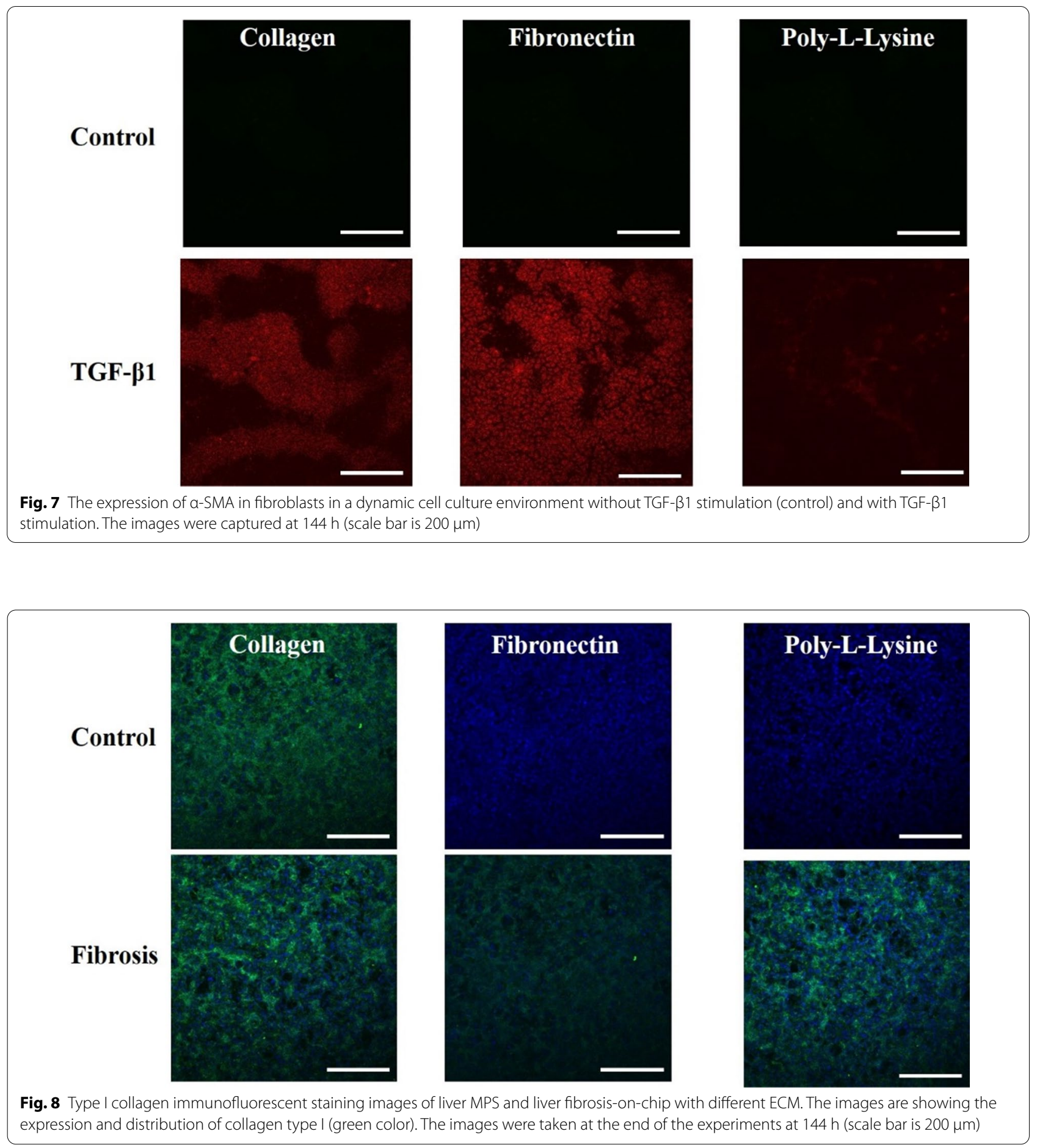

the MPS system. The effect of different ECM on the sensor and biochemical response was also evaluated. It was also found that fibronectin and collagen type I are the most useful ECM for studying fibrosis development within an MPS. However, poly-L-lysine can also be employed for such experiments. In short, chip embedded electrochemical sensors can be used to monitor fibrosis-related development within an MPS. 


\section{Abbreviations}

TEER: Trans-epithelial electrical resistance; TGF- $\beta 1$ : Transforming growth factor $\beta 1$; ROS: Reactive oxygen species; TJPs: Tight junction proteins; ECM: Extracellular Matrix; HSC: Hepatic stellate cells; OS: Oxidative stress; $\mathrm{H}_{2} \mathrm{O}_{2}$ : Hydrogen peroxide; $\mathrm{O}_{2}{ }^{--}$: Superoxide anions; $\mathrm{HO} \cdot:$ Hydroxyl radicals; ER: Endoplasmic reticulum; OOC: Organ-on-chip; MPS: Microphysiological systems; LOC Liver-on-chip; ECIS: Electrical cell-substrate impedance sensing; RTCA: Roche xCELLigence Analysis; PDMS: Polydimethylsiloxane; ITO: Indium tin oxide; CVD: Chemical vapor deposition; RPMI: Roswell Park Memorial Institute; FBS: Fetal bovine serum; P/S: Penicillin/streptomycin; CV: Cyclic voltammetry; PBS: Phosphate buffered saline; CLSM: Confocal laser scanning microscope; a-SMA: Alpha-smooth muscle actin; DPBS: Dulbecco's phosphate buffered saline; DAPI: 4',6-Diamidino-2-phenylindole; ZO-1: Zonula occludens-1.

\section{Acknowledgements}

The research was supported by the Program of National Research Foundation of Korea through the Ministry of Education and the Ministry of Trade, Industry and Energy (MOTIE) and Korea Institute for Advancement of Technology (KIAT) through the international Cooperative R\&D program (Project No. P0006848).

\section{Authors' contributions}

HMUF and BK conducted this study by conceptualizing the idea and utilizing the biosensors for on chip real time monitoring and assessment. MAUK and ARCS performed the cell culture on chip. KH and SHP developed the on-chip microfluidic channels and helped in experiments by setting up the platform. $\mathrm{DH}$ co-supervised this work and helped in concept designing. $\mathrm{KHC}$ approved and conducted this research work under his supervision. All authors read and approved the final manuscript.

\section{Funding}

The research was supported by the Program of National Research Foundation of Korea through the Ministry of Education.

\section{Availability of data and materials}

All data generated or analyzed during this study are included in this published article.

\section{Competing interests}

The authors declare that they have no competing interests.

\section{Author details}

${ }^{1}$ Department of Mechatronics Engineering, Jeju National University, Jeju-si, Republic of Korea. ${ }^{2}$ Department of Bioengineering, University of Pennsylvania, Philadelphia, USA.

Received: 15 December 2020 Accepted: 18 January 2021 Published online: 02 February 2021

\section{References}

1. T. Kisseleva, D. Brenner, Nat. Rev. Gastroenterol. Hepatol. 1, 1-16 (2020)

2. P. Ramachandran, R. Dobie, J. Wilson-Kanamori, E. Dora, B. Henderson, N. Luu, J. Portman, K. Matchett, M. Brice, J. Marwick, Nature 575(7783), 512 (2019)

3. J.A. Talwalkar, Nat. Rev. Gastroenterol. Hepatol. 7(1), 59 (2010)

4. T. Tsuchida, S.L. Friedman, Nat. Rev. Gastroenterol. Hepatol. 14(7), 397 (2017)

5. P. Vajro, S. Lenta, P. Socha, A. Dhawan, P. McKiernan, U. Baumann, O. Durmaz, F. Lacaille, V. McLin, V. Nobili, J. Pediatr. Gastroenterol. Nutr. 54(5), 700 (2012)

6. M. Parola, G. Robino, J. Hepatol. 35(2), 297 (2001)

7. V. Sánchez-Valle, N.C. Chavez-Tapia, M. Uribe, N. Méndez-Sánchez, Curr. Med. Chem. 19(28), 4850 (2012)

8. T. Luangmonkong, S. Suriguga, H.A. Mutsaers, G.M. Groothuis, P. Olinga, M. Boersema, in Reviews of Physiology, Biochemistry and Pharmacology, vol. 175, (Springer, New York, 2018), p. 71

9. J.P. Trivella, P. Martin, A.F. Carrion, Expert Opin. Emerg. Drugs 25(1), 59 (2020)
10. C.D. Edington, W.L.K. Chen, E. Geishecker, T. Kassis, L.R. Soenksen, B.M. Bhushan, D. Freake, J. Kirschner, C. Maass, N. Tsamandouras, Sci. Rep. 8(1), 1 (2018)

11. M. Gori, M.C. Simonelli, S.M. Giannitelli, L. Businaro, M. Trombetta, A. Rainer, PLOS ONE 11(7), e0159729 (2016)

12. J. Lee, B. Choi, D.Y. No, G. Lee, S.-R. Lee, H. Oh, S.-H. Lee, Integr. Biol. 8(3), $302(2016)$

13. H.M.U. Farooqi, M.A.U. Khalid, K.H. Kim, S.R. Lee, K.H. Choi, J. Micromech. Microeng. 30(11), 115013 (2020)

14. K.-J. Jang, M.A. Otieno, J. Ronxhi, H.-K. Lim, L. Ewart, K.R. Kodella, D.B. Petropolis, G. Kulkarni, J.E. Rubins, D. Conegliano, Sci. Transl. Med. 11(517), eaax5516 (2019)

15. H. Lee, J. Kim, Y. Choi, D.-W. Cho, ACS Biomater. Sci. Eng. 6(4), 2469 (2020)

16. H.-H. Huang, J. Zhou, Y.-P. Huang, J.-L. Kong, J. Anal. Chem. 63(5), 492 (2008)

17. Q. Zhou, D. Patel, T. Kwa, A. Haque, Z. Matharu, G. Stybayeva, Y. Gao, A.M Diehl, A. Revzin, Lab Chip 15(23), 4467 (2015)

18. K. Benson, S. Cramer, H.-J. Galla, Fluids Barriers CNS 10(1), 1 (2013)

19. S. Chen, R. Einspanier, J. Schoen, Histochem. Cell Biol. 144(5), 509 (2015)

20. O.Y. Henry, R. Villenave, M.J. Cronce, W.D. Leineweber, M.A. Benz, D.E. Ingber, Lab Chip 17(13), 2264 (2017)

21. B. Srinivasan, A.R. Kolli, M.B. Esch, H.E. Abaci, M.L. Shuler, J.J. Hickman, J. Lab. Autom. 20(2), 107 (2015)

22. X. Xie, R. Liu, Y. Xu, L. Wang, Z. Lan, W. Chen, H. Liu, Y. Lu, J. Cheng, RSC Adv. $\mathbf{5}(76), 62007$ (2015)

23. D. Bovard, A. Sandoz, K. Luettich, S. Frentzel, A. Iskandar, D. Marescotti, K. Trivedi, E. Guedj, Q. Dutertre, M.C. Peitsch, Lab Chip 18(24)، 3814 (2018)

24. H. Babahosseini, V. Srinivasaraghavan, Z. Zhao, F. Gillam, E. Childress, J.S. Strobl, W.L. Santos, C. Zhang, M. Agah, Lab Chip 16(1), 188 (2016)

25. M.W. van der Helm, O.Y. Henry, A. Bein, T. Hamkins-Indik, M.J. Cronce, W.D. Leineweber, M. Odijk, A.D. van der Meer, J.C. Eijkel, D.E. Ingber, Lab Chip 19(3), 452 (2019)

26. B.M. Maoz, A. Herland, O.Y. Henry, W.D. Leineweber, M. Yadid, J. Doyle, R. Mannix, V.J. Kujala, E.A. FitzGerald, K.K. Parker, Lab Chip 17(13), 2294 (2017)

27. N. Ferrell, R.R. Desai, A.J. Fleischman, S. Roy, H.D. Humes, W.H. Fissell, Biotechnol. Bioeng. 107(4), 707 (2010)

28. M. Ali, Y.S. Kim, M.A.U. Khalid, A.M. Soomro, J.-W. Lee, J.-H. Lim, K.H. Choi, L.S. Ho, Microelectron. Eng. 233, 111432 (2020)

29. F. Yin, Y. Zhu, M. Zhang, H. Yu, W. Chen, J. Qin, Toxicol. In Vitro 54, 105 (2019)

30. M. Malferrari, M. Becconi, S. Rapino, Anal. Bioanal. Chem. 411(19), 4365 (2019)

31. E. Ko, V.-K. Tran, Y. Geng, W.S. Chung, C.H. Park, M.K. Kim, G.H. Jin, G.H. Seong, J. Electroanal. Chem. 792, 72 (2017)

32. Z.H. Jin, Y.L. Liu, W.T. Fan, W.H. Huang, Small 16(9), 1903204 (2020)

33. W. Sun, Z. Luo, J. Lee, H.J. Kim, K. Lee, P. Tebon, Y. Feng, M.R. Dokmeci, S. Sengupta, A. Khademhosseini, Adv. Healthc. Mater. 8(4), 1801363 (2019)

34. M.A.U. Khalid, Y.S. Kim, M. Ali, B.G. Lee, Y.-J. Cho, K.H. Choi, Biochem. Eng. J. 155, $107469(2020)$

35. E.A. Nauman, K.J. Risic, T.M. Keaveny, R.L. Satcher, Ann. Biomed. Eng. 27(2), 194 (1999)

36. H. Rashidi, S. Alhaque, D. Szkolnicka, O. Flint, D.C. Hay, Arch. Toxicol. 90(7), 1757 (2016)

37. L. Kim, Y.-C. Toh, J. Voldman, H. Yu, Lab Chip 7(6), 681 (2007)

38. A.R.C. Salih, H.M.U. Farooqi, Y.S. Kim, S.H. Lee, K.H. Choi, Microelectron. Eng. 232, 111405 (2020)

39. A.B. Roberts, M.B. Sporn, R.K. Assoian, J.M. Smith, N.S. Roche, L.M. Wakefield, U.I. Heine, L.A. Liotta, V. Falanga, J.H. Kehrl, Proc. Natl. Acad. Sci. 83(12), 4167 (1986)

40. S.H. Lee, A.R. Paek, K. Yoon, S.H. Kim, S.Y. Lee, H.J. You, BMB Rep. 48(2), 115 (2015)

41. F. Pierucci-Alves, S. Yi, B.D. Schultz, Biol. Reprod. 86(2), 36 (2012)

42. B.K. Lal, S. Saito, P.J. Pappas, F.T. Padberg Jr., J.J. Cerveira, R.W. Hobson II., W.N. Durán, J. Vasc. Surg. 37(6), 1285 (2003)

43. H. Kwon, Y.S. Lee, M.O. Kim, M.Y. Chang, B.M. Won, B.S. Jin, S. Park, Cell Biochem. Funct. 32(8), 665 (2014)

44. R. Sobreiro-Almeida, D.R. Fonseca, N.M. Neves, Mater. Sci. Eng. C 103, 109866 (2019)

45. A. Mammoto, T. Mammoto, M. Kanapathipillai, C.W. Yung, E. Jiang, A Jiang, K. Lofgren, E.P. Gee, D.E. Ingber, Nat. Commun. 4(1), 1 (2013)

46. R.-M. Liu, L.P. Desai, Redox Biol. 6, 565 (2015) 
47. J. Ahamed, J. Laurence, Antioxid. Redox Signal. 27(13), 977 (2017)

48. L. Caja, P. Sancho, E. Bertran, D. Iglesias-Serret, J. Gil, I. Fabregat, Can. Res. 69(19), 7595 (2009)

49. B. Thapa, A. Walia, Indian J. Pediatr. 74(7), 663 (2007)

50. U.M. Zanger, M. Schwab, Pharmacol. Ther. 138(1), 103 (2013)

51. A.R. Ranade, M.S. Wilson, A.M. McClanahan, A.J. Ball, J. Toxicol. (2014). https ://doi.org/10.1155/2014/291054

52. P.C. Flannery, K.L. Abbott, S.R. Pondugula, Eur. J. Drug Metab. Pharmacokinet. 45(2), 297 (2020)

53. A. Veith, B. Moorthy, Curr. Opin. Toxicol. 7, 44 (2018)

54. M.J. Bollong, B. Yang, N. Vergani, B.A. Beyer, E.N. Chin, C. Zambaldo, D. Wang, A.K. Chatterjee, L.L. Lairson, P.G. Schultz, Proc. Natl. Acad. Sci. 114(18), 4679 (2017)

55. L.F. Correa, Y. Zheng, A.A. Delaney, Z. Khan, C.C. Shenoy, G.S. Daftary, Endocrinology 157(9), 3332 (2016)

56. N. Busso, C. Chesne, F. Delers, F. Morel, A. Guillouzo, Biochem. Biophys. Res. Commun. 171(2), 647 (1990)

57. J. Deng, Y. Cong, X. Han, W. Wei, Y. Lu, T. Liu, W. Zhao, B. Lin, Y. Luo, X. Zhang, Biomicrofluidics 14(6), 064107 (2020)
58. J. Deng, X. Zhang, Z. Chen, Y. Luo, Y. Lu, T. Liu, Z. Wu, Y. Jin, W. Zhao, B. Lin, Biomicrofluidics 13(2), 024101 (2019)

59. X. Li, S.M. George, L. Vernetti, A.H. Gough, D.L. Taylor, Lab Chip 18(17), $2614(2018)$

60. K. Zhang, H. Zhang, H. Xiang, J. Liu, Y. Liu, X. Zhang, J. Wang, Y. Tang, Int. J. Mol. Med. 32(2), 464 (2013)

61. W. Chen, J.B. Rock, M.M. Yearsley, L.D. Ferrell, W.L. Frankel, Hum. Pathol. 45(1), 160 (2014)

62. H.K. Kleinman, D. Philp, M.P. Hoffman, Curr. Opin. Biotechnol. 14(5), 526 (2003)

63. F. Tonon, G.G. Giobbe, A. Zambon, C. Luni, O. Gagliano, A. Floreani, G. Grassi, N. Elvassore, Sci. Rep. 9(1), 1 (2019)

64. L.A. Vernetti, N. Senutovitch, R. Boltz, R. DeBiasio, T. Ying Shun, A. Gough, D.L. Taylor, Exp. Biol. Med. 241(1), 101 (2016)

\section{Publisher's Note}

Springer Nature remains neutral with regard to jurisdictional claims in published maps and institutional affiliations.

\section{Submit your manuscript to a SpringerOpen ${ }^{\circ}$ journal and benefit from:}

- Convenient online submission

- Rigorous peer review

- Open access: articles freely available online

- High visibility within the field

- Retaining the copyright to your article

Submit your next manuscript at $\boldsymbol{\nabla}$ springeropen.com 